\title{
A case report: a giant cardiac atypical lipoma associated with pericardium and right atrium
}

\author{
Xin Wang ${ }^{1}$, Xiaona $\mathrm{Yu}^{1 *} \mathbb{D}$, Weidong Ren ${ }^{1}$ and Dongyu $\mathrm{Li}^{2}$
}

\begin{abstract}
Background: Among primary cardiac tumors, atypical lipoma is very rare. In particular, cases with lipomas in both the pericardium and the atria are even rare.

Case presentation: We report the case of a 49-year-old male patient presented to our department because of chest pain. Echocardiography revealed two large masses in both the pericardium and the right atrium. Then the tumors were completely resected and the histopathological examination revealed atypical lipoma. The patient recovered well without any complication and discharged from hospital.

Conclusions: We report a very rare case of a huge atypical lipomas located on the pericardium and right atrium. These tumors were easily detected by echocardiography and final diagnosed after surgical resection and pathological examination.
\end{abstract}

Keywords: Atypical lipoma, Echocardiography, Cardiac tumor

\section{Background}

Primary cardiac tumor are not conmen and the incidence range of $0.0017-0.28 \%$ as reported in autopsy studies [1]. One quarters of cardiac tumors can be categorized as malignant tumor on histology. The most common malignant tumors of the heart is angiosarcoma whereas atypical lipomas represent $<1 \%[2,3]$. Cardiac atypical lipomas are usually found incidentally because of asymptomatic, and in most cases require treatment or surgical intervention. We report a case of a 49 -year-old male patient was referred to our hospital because of chest pain. Echocardiography revealed a giant mass in the pericardial cavity, and another mass in the right atrium.

\section{Case presentation}

A 49-year-old male was admitted to our hospital because of chest pain over 20 days. Physical examination and electrocardiography were normal. Transthoracic echocardiography

\footnotetext{
* Correspondence: 1440114556@qq.com

${ }^{1}$ Department of Ultrasound, Shengjing Hospital of China Medical University,

Shenyang, China No.36, Sanhao Street, Heping District, Shenyang City

110004, China

Full list of author information is available at the end of the article
}

showed a giant solid echogenic mass in the pericardial cavity (Fig. 1). The size of the mass was about $16.2 \times 10.5$ $\mathrm{cm}$. Another echogenic mass measuring $4.8 \times 3.1 \mathrm{~cm}$ was observed in the right atrium (Fig. 2). The right atrial mass has a significant degree of activity with the cardiac cycle. During diastole period, the mass moved toward the tricuspid valve orifice, but did not enter the right ventricle. The tricuspid valve orifice blood flow was not obstructed. There was no blood flow signal within the two masses. These findings were confirmed by chest magnetic resonance imaging (Fig. 3). At surgery, the pericardium was opened, a giant mass measuring $15 \mathrm{~cm} \times 12 \mathrm{~cm} \times 8 \mathrm{~cm}$ was found in the pericardial cavity, another yellowish fatty mass was revealed in the right atrium (Fig. 4). Then the tumors were completely resected and the resected material was sent for pathological study. Macroscopic inspection revealed several multilobulated fatty masses (Fig. 5). Histologic examination showed adipocytes and confirmed the diagnosis of atypical lipoma (Fig. 6). The patient's postoperative course was uneventfully and he recovered quickly.

\section{Discussion and conclusions}

Liposarcoma-a mesenchymal malignant tumor that contains lipoblasts-is the most common soft tissue sarcoma 


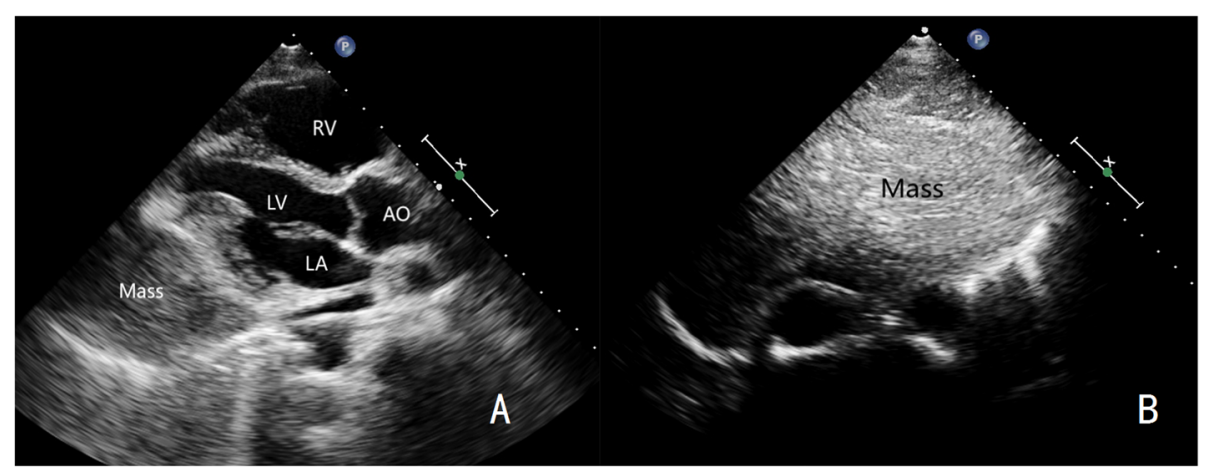

Fig. 1 a Left ventricular long axis view shows a large mass in the pericardium. b Subxiphoid view shows a giant mass in the pericardium. LA, left atrium; LV, left ventricle; RV, right ventricle; AO: aorta

and accounts for $20 \%$ of all mesenchymal tumors [4]. The tumor occurs most frequently in the limbs and retroperitoneum and rarely originates in the heart [5]. Peak incidence is between 40 and 60 years old, and there is a slight male predominance [6]. Liposarcoma of the heart is an extremely rare sarcoma, with less than 35 cases reported in the literature according to literature [7]. To our best knowledge, this is the first reported case of simultaneous atypical lipoma in the right atrium and pericardium.

Liposarcomas can be divided into four subtypes: Welldifferentiated liposarcoma (or atypical lipoma), myxoid/ round cell liposarcoma, pleomorphic liposarcoma, and dedifferentiated liposarcoma. Atypical lipoma was the most common subtype (50\%), which had been observed in the atrium and the pericardium. The tumor usually grows slowly, insidious and remain asymptomatic until reach a giant size. Atypical lipomas can be asymptomatic or symptomatic depending on their size and location within the heart. They can invade adjacent organs, so they are more likely to be symptomatic than benign lipomas. Atypical lipomas have a mild biological behavior and do not generally metastasis, but there is a possibility of focal recurrence.

Although pathological diagnosis serves as a gold standard of diagnosis of atypical lipoma, echocardiography is still essential. Echocardiography is an ideal and important diagnostic modality since it can provide information of the tumor on the size, location, boundary, modality, amount blood flow and so on. Although echocardiography offers a simple and non-invasive approach, it cannot conclusively differentiate between atypical lipomas and other primary tumors of the heart. Computed tomography or magnetic resonance imaging may be of additional value.

There are several diseases should be differentiated from atrial atypical lipomas, namely myxoma, thrombus, benign lipoma. Atrial myxoma is the most frequent primary cardiac tumor in adults. It usually arises in the area of the fossa ovalis, grows on pedicles, has the manner of soft and polyps. The tumor may move towards the ventricle during diastole. Atrial thrombus is usually associated with a history of atrial fibrillation or rheumatic heart disease, and ventricular thrombosis

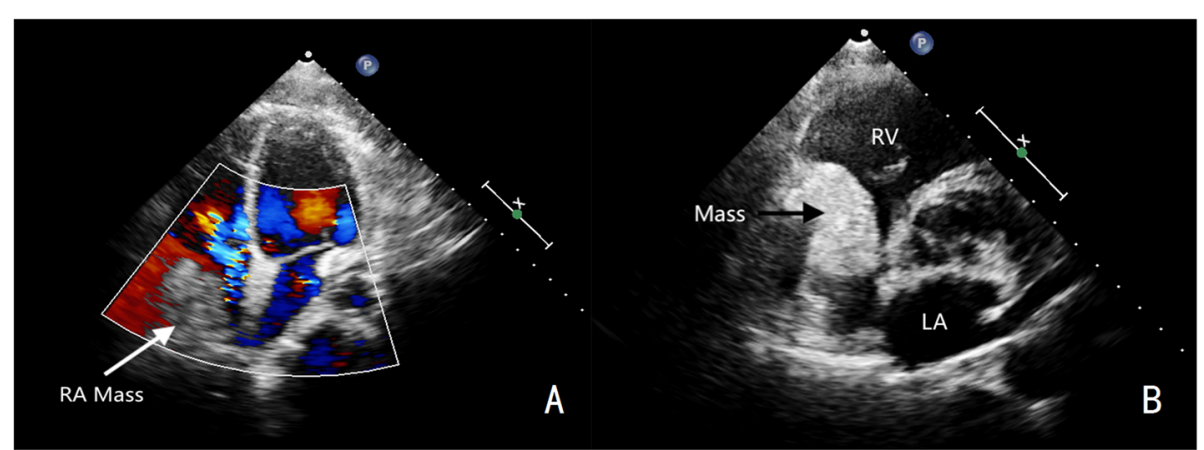

Fig. 2 a The apical four chamber view demonstrates the right atrial mass (arrow), there is no blood flow signal within the mass. b During diastolic period, the mass (arrow) moves toward the tricuspid valve orifice, but does not enter the right ventricle. LA, left atrium; RV, right ventricle 


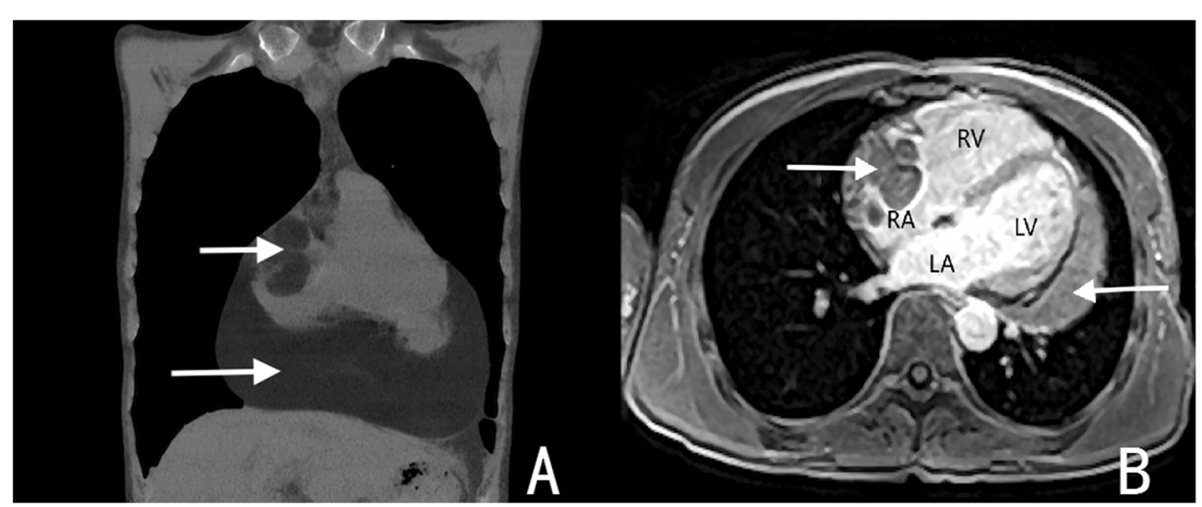

Fig. 3 Magnetic resonance imaging examination. a In the coronal section, shows the pericardium and atrial mass (arrow) $\mathbf{b}$ In the long axis four chamber view, shows the pericardium and atrial mass (arrow)

usually occurs on the basis of abnormal wall motion. The base of the thrombus is wide and can have activity. As time progresses, the echo of the thrombus can gradually change. The size of the thrombus may change after anticoagulant therapy. Cardiac benign lipomas can originate either from the subendocardium (50\%), subpericardium (25\%), or myocardium (25\%) and maybe located more frequently in the left ventricle or right atrium [8]. Cardiac benign lipomas are most often detected incidentally and do not have specific ultrasound findings. The lipoma demonstrated typical loss of signal

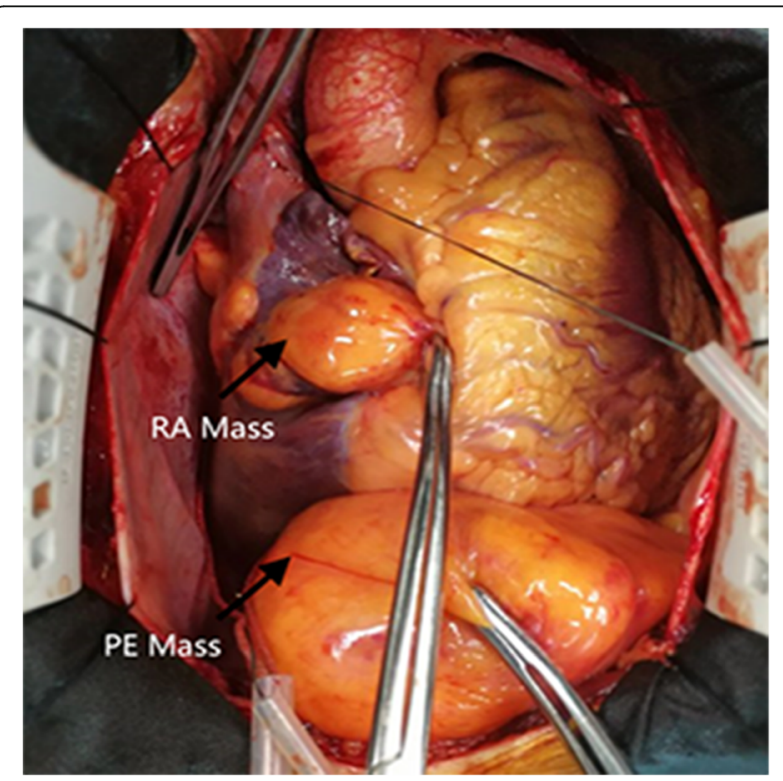

Fig. 4 An intraoperative photograph shows a giant mass which locates in the pericardial cavity, another yellowish fatty mass is revealed in the right atrium on fat suppressed magnetic resonance imaging sequence techniques.

Pericardial atypical lipomas may confuse with malignant mesothelioma, pericardial cyst, hemangiomas. The ultrasound manifestations of malignant mesothelioma usually include pericardial effusion, pericardial thickening, pericardial cavity mass. Pericardial cysts are usually congenial lesion or acquired [9]. Echocardiography showed an isolated, unilocular, smooth-walled cystic mass adjacent to the heart. There was no communicating tract between mass and heart cavity, and no blood flow signal within the mass. Cardiac hemangiomas are extremely rare and account for approximately $2 \%$ of all primary resected cardiac tumors. They can locate in atrium、ventricle, pericardium and endocardium [10]. Echocardiography usually presents as a hyperechoic mass with a well-defined boundary, and myocardial contrast echocardiography can demonstrate the vascularity of the mass.

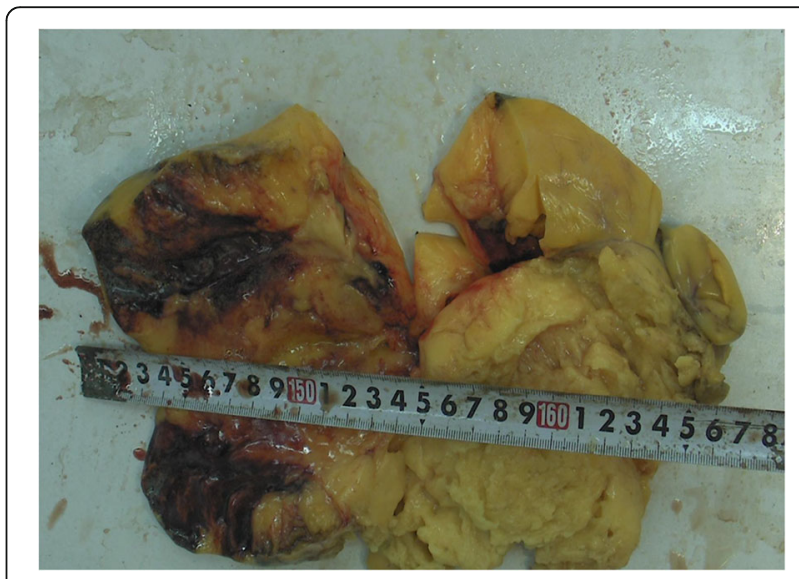

Fig. 5 Macroscopic inspection reveals several multilobulated fatty mass 


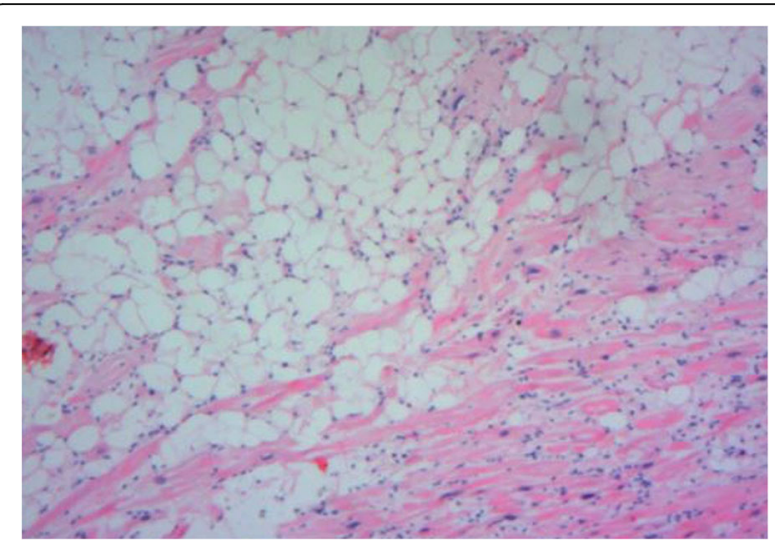

Fig. 6 Pathological examination shows a sheet-like arrangement of adipocyte. The nuclei of local lesion cells slightly enlarge (H\&E staining; magnification, $\times 20$ ). H\&E, haematoxylin and eosin

In conclusion, we report a very rare case of a huge atypical lipomas located on the pericardium and right atrium. These tumors were easily detected by echocardiography and final diagnosed after surgical resection and pathological examination. He is under follow-up for the possibility of recurrence.

\section{Acknowledgements}

None.

\section{Author's contributions}

XW drafted the manuscript. XNY interpreted and revised the manuscript. WDR is involved in ultrasound diagnosis. DYL is the surgeon of the case. All authors read and approved the final manuscript.

\section{Funding}

National Natural Science Foundation of China provided funding for this project. Dr. Weidong Ren is funded through China Medical University. Funding support was used to the travel-related expenses for patient followup. There were no honoraria.

\section{Availability of data and materials}

The datasets used in the case are available from the corresponding author upon reasonable request.

\section{Ethics approval and consent to participate}

This study was approved by the Ethical Committee of Shengjing Hospital of China Medical University. Written informed consent was obtained from individual participant.

\section{Consent for publication}

Written informed consent was obtained from the patient for publication of this case report and any accompanying images. A copy of the written consent is available for review by the Editor-in-Chief of this journal.

\section{Competing interests}

The authors declare that they have no competing interests.

\section{Author details}

'Department of Ultrasound, Shengjing Hospital of China Medical University, Shenyang, China No.36, Sanhao Street, Heping District, Shenyang City 110004, China. ${ }^{2}$ Department of Cardiac surgery, Shengjing Hospital of China Medical University, Shenyang, China.
Received: 29 July 2019 Accepted: 10 October 2019

Published online: 06 November 2019

\section{References}

1. Jayaprakash S. Clinical presentations, diagnosis, and management of arrhythmias associated with cardiac tumors. J Arrhythm. 2018;34(4):384-3.

2. Paraf F, Bruneval P, Balaton A, Deloche A, Mikol J, Maitre F. Primary liposarcoma of the heart. Am J Cardiovasc Pathol. 1990;3(2):175.

3. Hoffmeier A, Sindermann JR, Scheld HH, Martens S. Cardiac tumorsdiagnosis and surgical treatment. Deutsches Arzteblatt International. 2014; 111(12):205.

4. Tseng WW, Somaiah N, Lazar AJ, Lev DC, Pollock RE. Novel systemic therapies in advanced liposarcoma: a review of recent clinical trial results. Cancers. 2013;5(2):529.

5. Hisata Y, Tasaki Y, Kozaki S, Yamada T. A case of dedifferentiated liposarcoma of the heart and stomach. Int J Surg Case Rep. 2017;41:36-8.

6. Grethlein SJ. Histology driven systemic therapy of liposarcoma-ready for prime time? Transl Gastroenterol Hepatol. 2018;3:96.

7. He D, Chen M, Chen H, Liao D, Wang X, Zhang Z. Primary cardiac dedifferentiated liposarcoma with homologous and heterologous differentiation: a case report. Int J Clin Exp Pathol. 2015;8(8):9662.

8. Ismail I, Al-Khafaji K, Mutyala M, Aggarwal S, Cotter W, Hakim H. Cardiac lipoma. J Community Hosp Intern Med Perspect. 2015;5(5):28449.

9. Kar SK, Ganguly T. Current concepts of diagnosis and management of pericardial cysts. Indian Heart J. 2017;69(3):364-70.

10. Papadopoulos K, Makrides CA, Eleutheriou E. A cardiac haemangioma: The contribution of myocardial contrast echocardiography in the diagnosis. BMJ Case Reports. 2015;2015:bcr2015210075.

\section{Publisher's Note}

Springer Nature remains neutral with regard to jurisdictional claims in published maps and institutional affiliations.

\section{Ready to submit your research? Choose BMC and benefit from:}

- fast, convenient online submission

- thorough peer review by experienced researchers in your field

- rapid publication on acceptance

- support for research data, including large and complex data types

- gold Open Access which fosters wider collaboration and increased citations

- maximum visibility for your research: over $100 \mathrm{M}$ website views per year

At BMC, research is always in progress.

Learn more biomedcentral.com/submissions 